\title{
Supramolecular materials: longer and safer gastric residence
}

Article

Accepted Version

Khutoryanskiy, V. (2015) Supramolecular materials: longer and safer gastric residence. Nature Materials, 14 (10). pp. 963964. ISSN 1476-1122 doi: https://doi.org/10.1038/nmat4432 Available at https://centaur.reading.ac.uk/44587/

It is advisable to refer to the publisher's version if you intend to cite from the work. See Guidance on citing.

Published version at: http://www.nature.com/nmat/journal/v14/n10/full/nmat4432.html

To link to this article DOI: http://dx.doi.org/10.1038/nmat4432

Publisher: Nature Publishing Group

All outputs in CentAUR are protected by Intellectual Property Rights law, including copyright law. Copyright and IPR is retained by the creators or other copyright holders. Terms and conditions for use of this material are defined in the End User Agreement.

\section{www.reading.ac.uk/centaur}

\section{CentAUR}

Central Archive at the University of Reading

Reading's research outputs online 


\section{Longer and safer gastric residence}

A supramolecular polymer that is stable in the acidic environment of the stomach but dissolves in the neutral$\mathrm{pH}$ environment of the intestines prolongs the safe retention of gastric devices.

\section{Vitaliy V. Khutoryanskiy}

In delivering a drug, a dosage form typically needs to pass several stages and overcome natural body-defence barriers before the drug molecules reach the target organ and provide a therapeutic effect. When a drug is administered orally the most common and acceptable way of drug delivery - solid dosage forms such as tablets or capsules quickly pass through the oesophagus, and disintegrate either in the stomach or in the small or large intestines. Dosage forms travelling through the gastrointestinal tract will experience different transit times and environmental conditions (determined by the solution $\mathrm{pH}$, water content, and the presence of enzymes and live bacteria, for instance; Fig. 1) ${ }^{1}$. Depending on the therapeutic needs and the nature of a dosage form, the drug should be released at a particular part of the gastrointestinal tract to be absorbed by its mucosal membranes.

To prolong the residence of dosage forms in the stomach, rapidly swelling superporous hydrogels ${ }^{2}$, floating systems ${ }^{3}$, and mucoadhesive formulations ${ }^{4}$ have been proposed. However, these materials and approaches typically provide modest retention effects (up to several hours only). Another viable strategy to prolong gastric residence is that of devices designed to expand/unfold to sizes greater than $2 \mathrm{~cm}$ in diameter, which temporary prevents their exit through the pylorus ${ }^{5}$. These devices are often made from elastomeric polymers to ensure their foldability. However, the greatest limitation in the use of this strategy is the risk associated with potential intestinal obstruction caused by the migration of non-degradable large components of these devices from the stomach. Now, Giovanni Traverso, Robert Langer and colleagues report in Nature Materials the design of $\mathrm{pH}$-responsive supramolecular gels that exhibit excellent stability and elasticity under the acidic conditions of the stomach, and that undergo dissolution in the less acidic conditions of the small and large intestines 6 .

The human stomach has evolved to digest food and then to pass it to the intestine for further transformation and absorption of nutrients. The acidic conditions in the stomach (with $\mathrm{pH}$ values in the range of 1-5) are supposed to facilitate food digestion and deactivate some harmful microorganisms. Typically, as with ingested food, dosage forms taken orally are expected to reside in the stomach for up to 2 hours (the average half gastric emptying time is around $80.5 \mathrm{~min})^{7}$, and then to move to the small intestine ${ }^{1}$. Although the majority of drugs taken orally are expected to be absorbed in the intestinal sections of the gastrointestinal tract, some therapeutic areas require the dosage forms to have longer residence in the stomach. This is important for the treatment of some stomach disorders (such as stomach ulcer) ${ }^{3}$, for bariatric interventions ${ }^{8}$, and also for diagnostic purposes ${ }^{9}$.

Traverso and co-authors developed the supramolecular gel by co-precipitating, from their aqueous mixtures, the synthetic polymers poly (methacrylic acid-co-ethylacetate) - a commercially available as a pharmaceutical excipient and poly(acryloyl 6-aminocaproic acid) (PA6ACA) - polymerised through radical initiation of the monomer acryloyl 6aminocaproic acid, a product of the reaction between 6-aminocaproic acid and acryloyl chloride. The gels, which formed through interchain hydrogen bonding, are elastic and exhibit enteric properties, that is, they can be re-dissolved in neutral or alkali environments as a result of the deprotonation of carboxylic groups and the dissociation of hydrogen bonds. The authors used the gels as key building blocks in combination with biodegradable polycaprolactone to fabricate prototype gastric-retentive devices, which were designed in the form of a ring that can be folded, inserted into oral gelatin capsules, administered, and monitored radiographically in vivo. In pigs, the gelatin capsules dissolved in the stomach within 15 minutes of ingestion, thus deploying the gastric-retentive devices in the original ring shape. Retention of the ring-shape devices in the stomach of pigs lasted for two to five days, but eventually led to their partial breakage (through the dissociation of one or two supramolecular gel linkers) and successful passage into the intestine. A less acidic environment in the intestine caused further dissolution of the supramolecular gel linkers and subsequent disintegration of the device into smaller pieces that safely passaged through the lower gastrointestinal tract without causing any obstruction (Fig. 2).

Fabrication of gastric-retentive devices with improved safety profiles using new materials may stimulate further research and hopefully lead to the clinical translation of the materials and associated technology. Moreover, the concept of using foldable, expandable and degradable devices could also be beneficial for urinary bladder-retentive devices and similar technology in other therapeutic areas.

Vitaliy V. Khutoryanskiy is at the School of Pharmacy, University of Reading, Berkshire RG6 6AD, UK. e-mail:v.khutoryanskiy@reading.ac.uk

References

1. Cook, M. T., Tzortzis, G., Charalampopoulos, D. \& Khutoryanskiy, V. V. J. Control. Release. 162, 56-67 (2012).

2. Chen, J. et al. J. Control. Release. 64, 39-51 (2000).

3. Yang, L., Eshraghi, J., Fassihi, R. J. Control. Release. 57, 215-222 (1999).

4. Mucoadhesive Materials and Drug Delivery Systems, Khutoryanskiy, V. V. (ed.) (John Wiley \& Sons, 2014).

5. Hwang, S. J., Park, H. \& Park, K. Crit. Rev. Ther. Drug 15, 243-284 (1998).

6. Zhang, S. et al. Nature Mater. 14, XXX-YYY (2014).

7. Hellmig, S. et al. J. Gastroenterol. Hepatol. 21, 1832-1838 (2006).

8. Kethu, S. R. et al. Gastrointest. Endosc. 76, 1-7 (2012).

9. Tao, H. et al. Adv. Mater. 24, 1067-1072 (2012). 


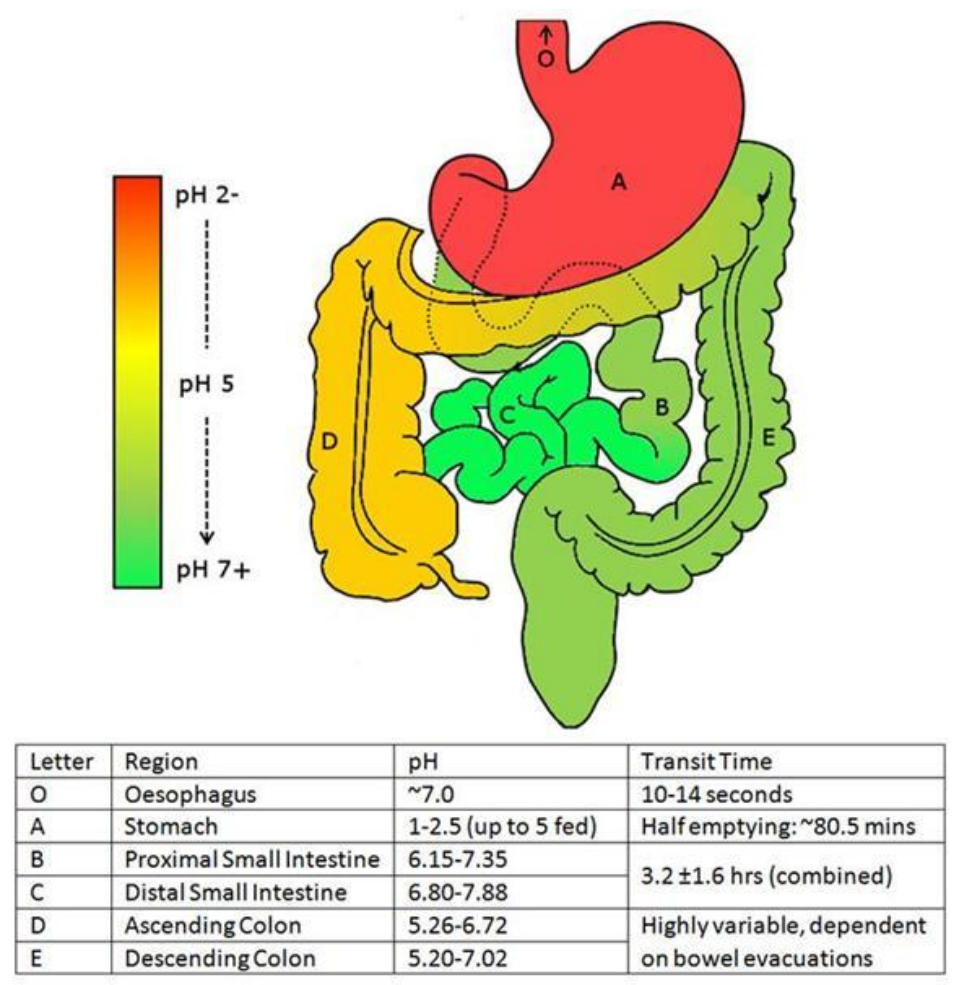

Figure 1 | Morphology of the human gastrointestinal tract, and pH values and transit times at different parts of the tract. Figure adapted with permission from ref. 1, (c) Elsevier.

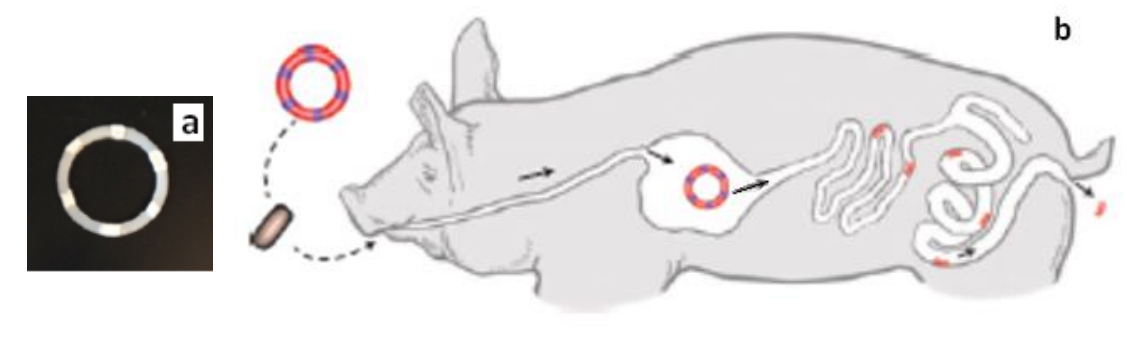

Figure 2 | A prototype gastric retentive device. $\mathbf{a}, \mathbf{b}$, Photograph of the device (a) and schematic of its administration and safe passage through a pig's gastrointestinal tract (b). Figure adapted from ref. 6, Nature Publishing Group. 